\title{
Influência de diferentes substratos na germinação de jambu (Spilanthes oleracea L. - Asteraceae)
}

\author{
Isabela Cristina Gomes Honório* \\ Vitor Batista Pinto \\ Jordany Aparecida Oliveira Gomes \\ Ernane Ronie Martins \\ Universidade Federal de Minas Gerais, Instituto de Ciências Agrárias \\ CEP 39.404-006, Montes Claros - MG, Brasil \\ *Autor para correspondência \\ isabelagomeshonorio@gmail.com
}

Submetido em 22/11/2010

Aceito para publicação em 12/04/2011

\section{Resumo}

O objetivo deste trabalho foi analisar a influência de diferentes substratos na germinação de sementes de Spilanthes oleracea L. (Asteraceae), espécie nativa da região Norte do Brasil. O experimento foi conduzido em delineamento inteiramente casualizado com seis tratamentos e quatro repetições com 25 sementes. Os tratamentos foram: substrato comercial Plantmax ${ }^{\circledR}$, solo+esterco (2:1), solo, areia lavada, casca de arroz parcialmente carbonizada e papel Germitest. Foi avaliada a germinação (\%), índice de velocidade de germinação (IVG) e comprimento da radícula $(\mathrm{mm})$. Houve apenas diferença no parâmetro comprimento da radícula, demonstrando valores inferiores quando utilizados substratos solo ou areia. Com exceção do solo, que apresentou médias inferiores em todas as variáveis observadas, os demais substratos são adequados para a germinação de $S$. oleraceae.

Palavras-chave: Índice de velocidade de germinação, Sementes, Substrato

\section{Abstract}

Influence of different substrates on the germination of jambu (Spilanthes oleracea $\mathrm{L}$. -Asteracea). The aim of this work was to analyze the influence of different substrates on the germination of Spilanthes oleracea L. (Asteraceae) seeds, a native species of northern Brazil. The experiment was conducted in a completely randomized design with six treatments and four replications, with 25 seeds each. The treatments consisted of the following substrates: commercial substrate Plantmax ${ }^{\circledR}$, soil + manure $(2: 1)$, soil, washed sand, partially carbonized rice peel and germitest paper. We evaluated the germination (\%), the germination rate index (GRI), and the radicle length. The results presented significant differences for the parameter radicle length, and lower values were shown when substrate soil or sand was utilized. With the exception of soil, that had lower averages for all analyzed parameters, the other substrates were found to be suitable for the germination of $S$. oleracea.

Key words: Germination speed index, Seeds, Substrate 


\section{Introdução}

A germinação constitui a fase do ciclo de vida que influencia diretamente a distribuição das plantas. Os estudos sobre a ecofisiologia da germinação e o conhecimento da biologia das sementes são importantes para que se compreendam todas as etapas de uma comunidade vegetal, bem como a sobrevivência e regeneração natural (BLACK; EL HADI, 1992; VÁZQUEZ-YANES; OROZCO-SEGOVIA, 1993).

De acordo com as prescrições das Regras para Análise de Sementes (BRASIL, 2009), a temperatura e o oxigênio têm fundamental importância na germinação e esses resultados devem refletir a capacidade das sementes em originar plântulas normais, sob condições e limites estabelecidos. Além disso, o substrato também influencia a germinação de sementes, sendo essa influência decorrente de suas características, como estrutura, grau de aeração, capacidade de retenção de água e grau de infestação de patógenos, dentre outras, as quais podem variar de acordo com o tipo de material utilizado (BARBOSA et al., 1990). O substrato deve manter a proporção adequada entre o conteúdo de água e a aeração, não devendo ser umedecido em excesso para evitar que a película de água envolva completamente a semente, restringindo a entrada e absorção do oxigênio (VILLAGOMEZ et al., 1979). Assim, a escolha do substrato deve ser feita levando-se em consideração o tamanho da semente, a exigência quanto ao suprimento de água e à sensibilidade ou não à luz e a facilidade que este oferece para realização das contagens e avaliação das plântulas (BRASIL, 2009).

Para Martins et al. (1999), uma germinação rápida e uniforme das sementes, seguida por imediata emergência das plântulas são características altamente desejáveis, pois quanto mais tempo a plântula permanecer nos estádios iniciais de desenvolvimento e demorar a emergir no solo, mais vulnerável estará às condições adversas do meio.

Assim, o presente trabalho foi conduzido com o objetivo de avaliar a influência de diferentes substratos sob a germinação de sementes de jambu (Spilanthes oleracea L.- Asteraceae), uma hortaliça amplamente utilizada na culinária e na medicina popular do Pará.

\section{Material e Métodos}

\section{Espécie estudada}

O jambu (Sphilanthes oleraceae L.) é planta da família Asteraceae, herbácea perene, semi-ereta e de ramos decumbentes, nativa da região Norte do país, usada como hortaliça condimentar e para fins medicinais. É também conhecido por agrião do Pará, agrião do Brasil, agrião do Norte, jabuaçu, erva maluca, jaburama, botão de ouro, entre outros (COUTINHO et al., 2006). É uma planta usada na medicina popular como analgésica, antigripal, antiespasmódica, antiasmática, antianêmica, antiinflamatória, antiescorbútica, béquica, carminativa, cicatrizante, desinfetante, digestiva, emenagoga, estimulante, estomáquica, excitante, febrífuga, odontálgica e sialagoga (LORENZI; MATOS, 2002). Segundo Armond (2007), em triagem química da parte aérea de plantas de jambu através da técnica de cromatografia de camada delgada, foi confirmada a presença de óleos essenciais em até 0,7\%, flavonóides, espilantina, espilantol, spilol, afinina, colina e fitosterina.

Trata-se de uma hortaliça amplamente utilizada também, na culinária paraense, ganhando destaque para o pato ao molho de tucupi e o tacacá. Assim, esta espécie é muito importante como fonte de renda para os agricultores familiares dos municípios do Pará, pois é considerada uma planta de múltiplo uso (medicinal, condimentar e ornamental), reunindo elementos essenciais para formação de um sistema sustentável (GUSMÃO et al., 2009).

\section{Influência do substrato na germinação de jambu}

O experimento foi realizado no Laboratório de Plantas Medicinais do Instituto de Ciências Agrárias da Universidade Federal de Minas Gerais (UFMG), na cidade de Montes Claros, MG. As sementes de jambu foram provenientes do estado do Pará, sendo selecionadas manualmente aquelas sem danos mecânicos e que apresentassem uniformidade (tamanho e forma semelhantes) e, em seguida, semeadas 25 sementes em caixa gerbox devidamente esterilizada com hipoclorito de sódio a $1 \%$. Os tratamentos consistiram em diferentes 
substratos: substrato comercial Plantmax ${ }^{\circledR}$, solo + esterco na proporção de 2:1, solo, areia lavada, casca de arroz parcialmente carbonizada e papel germiteste, sendo, este último, a testemunha. Os substratos utilizados foram previamente esterilizados em autoclave a $120^{\circ} \mathrm{C}$ por $1 \mathrm{~h}$. $\mathrm{O}$ experimento foi conduzido em câmara de germinação (BOD) a $25^{\circ} \mathrm{C}\left( \pm 2^{\circ} \mathrm{C}\right)$, num período de 15 dias e fotoperíodo de $24 \mathrm{~h}$ e; os substratos foram irrigados de acordo com a necessidade de água. O delineamento experimental utilizado foi o inteiramente casualizado com seis tratamentos e quatro repetições, totalizando 600 sementes. A contagem das sementes germinadas foi realizada diariamente até o $15^{\circ}$ dia, para posterior cálculo do índice de velocidade de germinação (IVG). As variáveis analisadas, além do IVG, foram porcentagem de germinação (GERM) e comprimento de raiz (COMPR) $(\mathrm{mm})$. Os dados em percentagem foram transformados em arco seno $(\mathrm{X} / 100)^{1 / 2}$. Os dados foram submetidos à análise de variância e teste de média (Scott-Knott a 5\% de probabilidade). De acordo com a Regra para Análise de Sementes (RAS) (BRASIL, 2009), como o experimento foi conduzido em BOD é usual utilizar na estatística o Delineamento Inteiramente Casualizado (DIC).

\section{Resultados e Discussão}

Os substratos não influenciaram as variáveis GERM, com exceção do tratamento com solo que foi estatisticamente inferior aos demais, e IVG (Tabela 2), já a variável COMPR diferiu estatisticamente das demais, resultados que podem ser evidenciados na Tabela 1 .

TABELA 1:Resumo da análise de variância de porcentagem de germinação (GERM), índice de velocidade de germinação (IVG) e comprimento de radícula (COMPR) de sementes de jambu (Spilanthes oleracea L. - Asteraceae) em diferentes substratos.

\begin{tabular}{ccccc}
\multirow{2}{*}{ FV } & \multirow{2}{*}{ GL } & \multicolumn{3}{c}{ Quadrados Médios } \\
\cline { 3 - 5 } & & GERM & IVG & COMPR \\
\hline Tratamentos & 5 & $218,99^{\text {ns }}$ & $23,07^{\text {ns }}$ & $290,62^{*}$ \\
Resíduos & 18 & 57,01 & 26,62 & 16,37 \\
Total & 23 & & & \\
\hline CV (\%) & & 11,63 & 16,83 & 22,42 \\
\hline
\end{tabular}

* - Significativo a $5 \%$ de probabilidade, pelo teste $\mathrm{F}$. ${ }^{\text {ns }}$ - Não significativo a $5 \%$ de probabilidade pelo teste $\mathrm{F}$.
TABELA 2: Valores médios da porcentagem de germinação (GERM), índice de velocidade de germinação (IVG) e comprimento de radícula (COMPR) de sementes de jambu (Spilanthes oleracea L.- Asteraceae) em diferentes substratos.

\begin{tabular}{cccc}
\hline Tratamentos & GERM & IVG & COMPR \\
\hline Substrato commercial & $62,17 \mathbf{a}$ & $27,05 \mathbf{b}$ & $18,34 \mathbf{b}$ \\
Solo+esterco & $69,04 \mathbf{a}$ & $32,72 \mathbf{a}$ & $15,01 \mathbf{b}$ \\
Solo & $50,94 \mathbf{b}$ & $23,42 \mathbf{b}$ & $9,55 \mathbf{c}$ \\
Areia & $69,51 \mathbf{a}$ & $36,39 \mathbf{a}$ & $12,42 \mathbf{c}$ \\
Germitest (testemunha) & $69,33 \mathbf{a}$ & $34,33 \mathbf{a}$ & $33,82 \mathbf{a}$ \\
Casca de arroz & $68,56 \mathbf{a}$ & $30,01 \mathbf{a}$ & $19,15 \mathbf{b}$ \\
carbonizada & & \\
\hline
\end{tabular}

As médias seguidas de pelo menos uma mesma letra minúscula na linha, não diferem significativamente entre si pelo teste de Scott-Knott a $5 \%$ de probabilidade.

A Figura 1 apresenta a percentagem de germinação das sementes de jambu em cada dia de avaliação, podendo ser observado que nenhum tratamento atingiu o número máximo de sementes germinadas (25). Além disso, ao final do último dia de avaliação, pode ser observado que algumas sementes, antes contadas como germinadas, morreram.

Isso pode ser explicado pelo fato do solo apresentar grande quantidade de argila, que pode ter dificultado o crescimento radicular. Dessa forma, observou-se que as variáveis porcentagem de germinação e índice de velocidade de emergência são favorecidas com a utilização de substratos com uma boa aeração e disponibilidade de água (SILVA et al., 2008). Para que ocorra a germinação das sementes e a emergência das plântulas, as sementes não precisam, inicialmente, de nutrientes, necessitando apenas de hidratação e aeração para que ocorram as reações que induzam a formação do caulículo e da radícula, sendo que uma boa porosidade do substrato permite o movimento de água e ar e favorece a germinação de forma mais rápida (SIMÃO, 1971).

Os tratamentos apresentaram desempenhos semelhantes para variável GERM, como observado no trabalho de Bezerra et al. (2004), que estudaram a germinação de Moringa oleifera Lam (Moringaceae). No referido estudo, foram utilizados os substratos vermiculita, Plantmax ${ }^{\circledR}$ e uma mistura composta de solo 


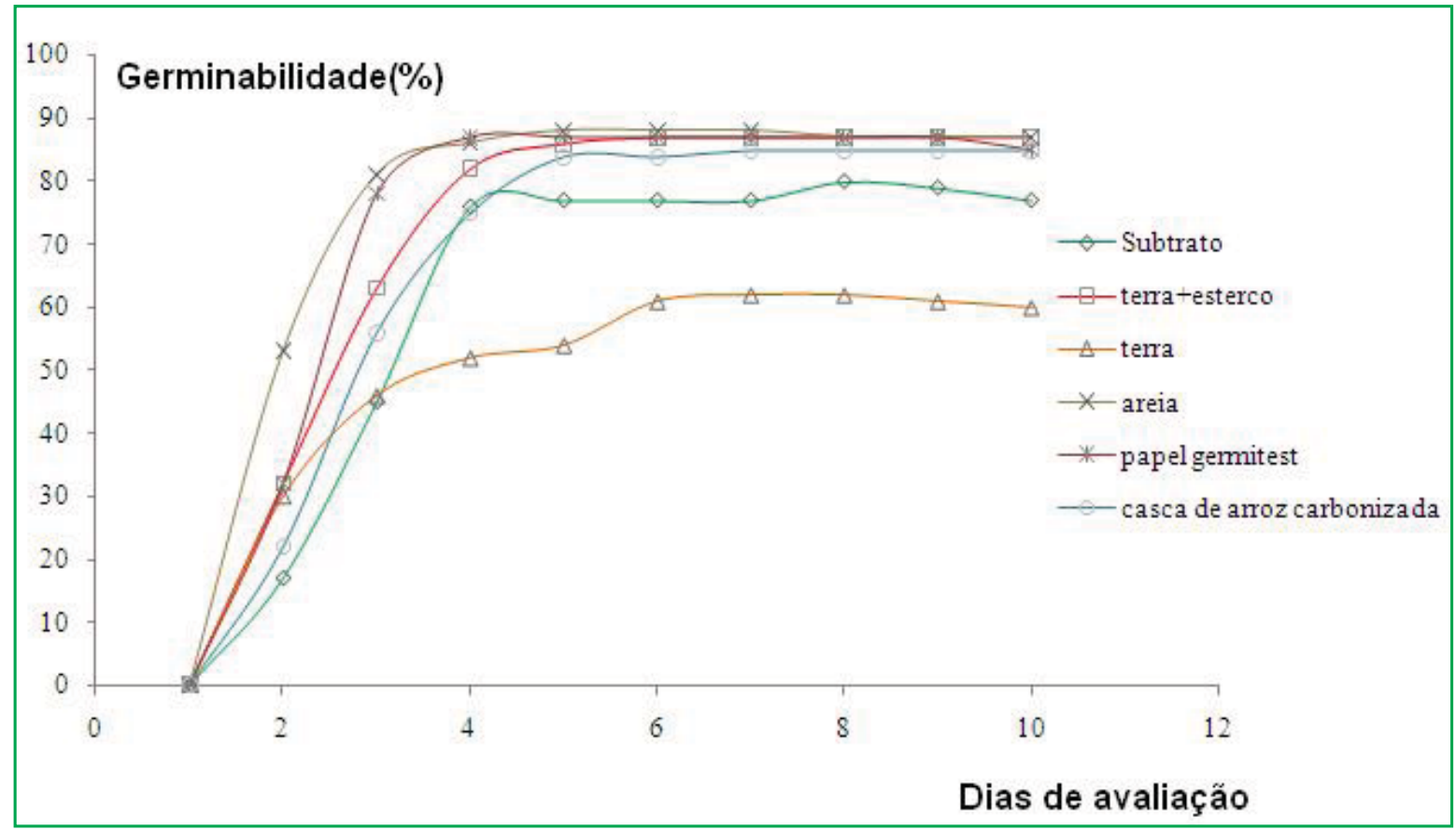

FIGURA 1: Percentagem de germinação ao longo dos dias de avaliação das sementes de jambu (Spilanthes oleracea L. - Asteraceae).

esterilizado, húmus de minhoca e pó de coco lavado, na proporção de $2: 1: 1$, porém, os diferentes tipos de substrato também não influenciaram a variável GERM. Por outro lado, resultados análogos também foram encontrados por Silveira et al. (2002) em tomateiro, onde foi verificado que em todos os tratamentos onde o pó de coco estava presente, houve uma boa germinação, provavelmente devido à alta capacidade de retenção de água desse substrato.

Ao ser realizada a primeira contagem das plântulas, indiretamente, realiza-se uma avaliação da velocidade de germinação, pois a maior porcentagem da primeira contagem significa que as sementes desta amostra germinaram mais rapidamente que nas demais (VIEIRA; CARVALHO, 1994). Na variável IVG, os tratamentos com substrato comercial e solo diferiram dos demais por apresentarem média inferior (Tabela 2), mostrando que as sementes nesses substratos demoraram um período maior para germinar.

Em trabalho realizado por Andrade et al. (1999) com sementes de palmiteiro (Euterpe edulis Mart.Arecaceae) foi demonstrado que o substrato comercial proporcionou os mais altos valores de protrusão de radícula (germinação), de plântulas normais e de velocidade de germinação de plântulas, diferindo, assim, do presente trabalho. No entanto, o mesmo substrato não apresentou diferença estatística quando comparado ao substrato areia, para valores de protrusão de radícula, resultados que também foram observados no presente trabalho.

Para a variável COMPR, os tratamentos com o Germitest apresentaram média estatisticamente superior, uma vez que proporcionou maior espaçamento entre as sementes. Porém os tratamentos com solo e areia alcançaram valores estatisticamente inferiores a todos os tratamentos, o que difere dos resultados observados por Silva et al. (2008), onde foi evidenciado o melhor desenvolvimento radicular no substrato areia devido, possivelmente, às suas características físicas. Já os tratamentos com substrato comercial, solo+esterco e casca de arroz carbonizada apresentaram valores intermediários aos demais (Tabela 2). Em experimento com moringa, realizado por Bezerra et al. (2004), o substrato que apresentou condições mais adequadas 
para o crescimento radicular foi o Plantmax, similar ao observado por Oliveira (2000) em sementes da mesma espécie. Já os tratamentos com substrato comercial, solo+esterco e casca de arroz carbonizada apresentaram valores intermediários aos demais.

Considerando os resultados obtidos, pode-se concluir que, a exceção do solo, que apresentou índices inferiores às demais variáveis observadas em relação à porcentagem de germinação, índice de velocidade de germinação e comprimento da radícula, todos os demais substratos podem ser utilizados na produção de mudas do jambu.

\section{Agradecimentos}

Ao Programa de Educação Tutorial (PET Agronomia).

\section{Referências}

ANDRADE, A. C. S.; LOUREIRO, M. B.; SOUZA, A. D. O.; RAMOS, F. N.; CRUZ, A.P.M. Reavaliação do efeito do substrato e da temperatura na germinação de sementes de palmiteiro (Euterpe edulis Mart.). Revista Árvore, Viçosa, v. 23, p. 279-283, 1999.

ARMOND, C. Indicadores químicos, crescimento e bioeletrografias de plantas de jambu (Acmella oleracea L.), capim-limão (Cymbopogon citratus (DC) Stapf) e folha-dafortuna (Bryophyllum pinnatum (Lam.) Oken) submetidas a tratamentos homeopáticos. 2007. 142 f. Tese (Doutorado em Fitotecnia) - Universidade Federal de Viçosa, Viçosa. 2007.

BARBOSA, J. M.; BARBOSA, L. M.; SILVA, T. S.; FERREIRA,

D. T. L. Influência de substratos e temperaturas na germinação de sementes de duas frutíferas silvestres. Revista Brasileira de Sementes, Londrina, v. 12, n. 2, p. 66-73, 1990.

BEZERRA, A. M. E.; MOMENTÉ, V. G.; MEDEIROS FILHO, S. Germinação de sementes e desenvolvimento de plântulas de moringa (Moringa oleifera Lam.) em função do peso da semente e do tipo de substrato. Horticultura Brasileira, Brasília, v. 22, n. 2, p. 295-299, 2004.
BLACK, R.; EL HADI, F. M. Presouring treatments of Acacia senegal seed: germination and growth. Agricultura Tropical, Mato Grosso, v. 69, p. 15-20, 1992.

BRASIL. Ministério da Agricultura e Reforma Agrária. Regras para análise de sementes. Brasília: SNDA/DNDV/CLAV, 2009. $365 \mathrm{p}$.

COUTINHO, L. N.; APARECIDO, C. C.; FIGUEIREDO, M. B. Galhas e deformações em jambu (Spilanthes oleraceae L.) causadas por Tecaphora spilanthes (Ustilaginales). Summa Phytopathology, Botucatu, v. 32, p. 283-285, 2006.

GUSMÃO S. A. L.; GUSMÃO M. T. A.; SILVESTRE W. V. D.; LOPES P. R. A. Caracterização do cultivo de jambu nas áreas produtoras que abastecem a grande Belém. In: CONGRESSO BRASILEIRO DE OLERICULTURA, 49, 2009, Águas de Lindóia. Resumos... Águas de Lindóia: CBO, 2009. Versão eletrônica.

LORENZI H.; MATOS F. J. A. Plantas medicinais no Brasil: nativas e exóticas cultivadas. São Paulo: Instituto Plantarum, 2002. $396 \mathrm{p}$.

MARTINS C. C.; NAKAGAWA J.; BOVI, M. L. A. Efeito da posição da semente no substrato e no crescimento inicial das plântulas de palmito-vermelho. Revista Brasileira de Sementes, Londrina, v. 21, p. 164-173, 1999.

OLIVEIRA, V. C. Germinação de sementes de moringa (Moringa oleifera Lam.). 2000. 29 f. Monografia (Graduação em Ciências Agrárias) - Universidade Federal do Ceará, Fortaleza. 2000.

SILVA, E. A.; MENDONÇA, V.; TOSTA, M. S.; OLIVEIRA, A. C.; SMARSI, R. C.; MENEGAZZO, M. L. Efeito de diferentes substratos na produção de mudas de cultivares de almeirão. Agrarian, Dourados, v. 1, n. 1, p. 55-65, 2008.

SILVEIRA, E. B.; RODRIGUES, V. J. L. B.; GOMES, A. M. A.; MARIANO, R. L. R.; MESQUITA, J. C. P. Pó de coco como substrato para produção de mudas de tomateiro. Horticultura Brasileira, Brasília, v. 20, n. 2, p. 211-216, 2002.

SIMÃO, S. Manual de fruticultura. São Paulo: Ceres, 1971. 530 p. VÁZQUEZ-YANES, C.; OROZCO-SEGOVIA, A. Patterns of seed longevity and germination in the rainforest. Annual Review of Ecology and Systematics, Palo Alto, v. 24, p. 69-87, 1993.

VIEIRA R. D.; CARVALHO, N. M. Testes de vigor em sementes. Jaboticabal: FUNEP. 1994. 164 p.

VILLAGOMEZ, A. Y.; VILLASENOR, R. R.; SALINAS, M. J. $R$. Lineamento para el funcionamento de um laboratorio de semillas. Mexico: INIA, 1979. $128 \mathrm{p}$. 